\title{
Combining Natural and Engineered Host Plant Resistance Mechanisms in Potato for Colorado Potato Beetle: Choice and No-choice Field Studies
}

\author{
Joseph J. Coombs, David S. Douches', and Susannah G. Cooper \\ Department of Crop and Soil Sciences, Michigan State University, East Lansing, MI 48824
}

Edward J. Grafius and Walter L. Pett

Department of Entomology, Michigan State University, East Lansing, MI 48824

Dale D. Moyer

Cornell Cooperative Extension of Suffolk, Long Island Horticultural Research and Extension Center, Riverhead, NY 11901

\begin{abstract}
AdDITIONAL INDEX WORDs. Solanum tuberosum, Leptinotarsa decemlineata, Bacillus thuringiensis, cry3A, glycoalkaloids, glandular trichomes, resistance gene pyramiding

Abstract. Colorado potato beetle (Leptinotarsa decemlineata Say) is the leading insect pest of potato (Solanum tuberosum L.) in northern latitudes. Host plant resistance is an important tool in an integrated pest management program for controlling insect pests. Field studies were conducted to compare natural host plant resistance mechanisms (glandular trichomes and Solanum chacoense Bitter-derived resistance), engineered [Bacillus thuringiensis (Bt) Berliner Bt-cry $3 A$ ], and combined (glandular trichomes $+B t$-cry $3 A$ and $S$. chacoense-derived resistance $+B t$-cry $3 A$ transgenic potato lines) sources of resistance for control of colorado potato beetle. Six different potato clones representing five different host plant resistance mechanisms were evaluated for 2 years in a field situation under natural colorado potato beetle pressure in Michigan and New York, and in a no-choice field cage study in Michigan. In the field studies, the $S$. chacoensederived resistance line, $B t$-cry $3 A$ transgenic, and combined resistance lines were effective in controlling defoliation by colorado potato beetle adults and larvae. Effectively no feeding was observed in the $B t$-cry $3 A$ transgenic lines. The glandular trichome line suffered less defoliation than the susceptible control, but had greater defoliation than the $B t$ cry $3 A$ transgenic lines and the $S$. chacoense-derived resistance line. In the no-choice cage study, the $B t$-cry $3 A$ transgenic lines and the combined resistance lines were effective in controlling feeding by colorado potato beetle adults and larvae with no defoliation observed. The $S$. chacoense-derived resistance line and the glandular trichome line suffered less defoliation than the susceptible control. Based on the results of the field trials and no-choice field cage studies, these host plant resistance mechanisms could be used to develop potato varieties for use in a resistance management program for control of colorado potato beetle.
\end{abstract}

The colorado potato beetle is the most serious insect pest of potatoes throughout the eastern and north central United States and Canada. Control of the colorado potato beetle has relied almost entirely on pesticides for over 125 years (Casagrande, 1987). Throughout its history, the colorado potato beetle has shown the ability to adapt to every insecticide used for its control (Bishop and Grafius, 1996). Currently, it has developed resistance to 41 insecticides, including organophosphates, carbamates, organochlorines, pyrethroids, hydrogen cyanide, and more recently the neonicotinoids imidacloprid and thiamethoxam (Byrne et al., 2004; Georgiou and Lagunes-Tejeda, 1991; Whalon et al., 2004).

Host plant resistance is a central component of a practical longterm solution for controlling the colorado potato beetle in potato. No potato varieties resistant to colorado potato beetle are currently available. Glandular trichomes and leptine glycoalkaloids are two of the most thoroughly investigated natural insect host plant resistance mechanisms available in potato. The glandular trichomes of the wild Bolivian potato, Solanum berthaultii Hawkes, confer resistance to at least ten major insect pests, including the colorado potato beetle (Tingey, 1991). The presence of Type A and B trichomes in S. berthaultii leads to entrapment and death of

Received for publication 4 Mar. 2005. Accepted for publication 7 May 2005. This publication was made possible through support provided by the Michigan Agriculture Experiment Station, USDA/ARS cooperative agreement 59-07902-060, and the Michigan Potato Industry Commission. small-bodied insects and reduces developmental time, survival, and oviposition of colorado potato beetle (Yencho and Tingey, 1994). However, in a no-choice situation, colorado potato beetle rapidly adapted to $S$. berthaultii (Groden and Casagrande, 1986). NYL235-4, the glandular trichome clone evaluated in this study, is the result of a series of backcrosses from $S$. berthaultii, with reported resistance to colorado potato beetle (Plaisted et al., 1992). Leptine glycoalkaloids have been defined as effective natural resistance mechanisms of potato against colorado potato beetle, but are found in only a few accessions of S. chacoense (Sinden et al., 1986a, 1986b). The North Dakota State University breeding line ND5873-15 (ND4382-19 x 'Chipeta') evaluated in this study has shown resistance to colorado potato beetle in the field, derived from S. chacoense (Lorenzen et al., 2001).

The insecticidal proteins produced by $B t$ target specific orders of insects and have no known toxicity to mammals or birds (Lavrik et al., 1995). Bacillus thuringiensis subsp. tenebrionis produces the Cry3A $\delta$-endotoxin, which is toxic to Coleoptera, including colorado potato beetle (Krieg et al., 1983). Bt-transgenic potatoes have been developed for resistance to colorado potato beetle and potato tuberworm (Phthorimaea operculella Zeller) (Douches et al., 1998; Perlak et al., 1993; Sutton et al., 1992). Coombs et al. (2002) transformed potato clones that have natural host plant resistance mechanisms (glandular trichomes and leptine glycoalkaloids) with a synthetic $B t$-cry3 $A$ gene. 
Use of combined resistance mechanisms in a single variety has been suggested as a strategy for delaying the development of insect adaptation to host plant resistance mechanisms, especially Bt (Cooper et al., 2004; Gould, 1998; McGaughey et al., 1998; Tabashnik, 1994). The colorado potato beetle has demonstrated the ability to develop resistance to Bt Cry3A in the lab (Whalon et al., 1993) and to glandular trichome-based resistance (Groden and Casagrande, 1986). Our strategy was to combine in potato genotypes, different sources of natural and engineered host plant resistance mechanisms. These natural host plant resistance mechanisms, combined with engineered $B t$-transgenic resistance, should increase the durability and efficacy of host plant resistance to the colorado potato beetle. The objective of this study was to evaluate various natural, engineered, and combined host plant resistance mechanisms in potato to control colorado potato beetle and reduce defoliation in the field and in $8-\mathrm{m}^{3}$ screen cages.

\section{Materials and Methods}

Six different potato clones representing five different host plant resistance mechanisms were evaluated in this study (Table 1). Nontransgenic potato clones included: NYL235-4 with glandular trichomes (Plaisted et al., 1992); ND5873-15 with field resistance to colorado potato beetle (provided by Drs. R. Novy and J. Lorenzen at North Dakota State Univ.); and 'Norwis' (susceptible control).

The Bt-cry3A (coleopteran specific) gene used for transformation of the transgenic potato lines in this study was supplied by Dr. J. Kemp at New Mexico State Univ. (Sutton et al., 1992). The constitutive $\mathrm{OCS}_{3}$ mas promoter (Ni et al., 1995) was used to express $B t$-cry $3 A$ and the $B t$-cry $3 A$ transgenic potato lines were generated using Agrobacterium tumefaciens Smith and Townsend-mediated transformation (Coombs et al., 2002): The Bt-cry3A transgenic clones containing single or combined resistance factors (ND5c3.1, NYLc3.3, and NORc3.8) used in this study were developed in our lab (Table 1).

$B t$-Cry $3 A$ concentration in the foliage of the three Bt-cry3Atransgenic lines was determined using a Bt-Cry3A ELISA kit (Agdia, Elkhart, Ind.). Leaf samples (three to four leaves down from the top of the plant) were collected from 60-d-old fieldgrown plants in the cage study. Samples $(75 \mathrm{mg})$ were placed in Agdia tissue homogenizer envelopes and placed at $-80{ }^{\circ} \mathrm{C}$. Samples were homogenized in $20 \mu \mathrm{L}$ of the extraction buffer and then diluted 1:500. ELISA was done using $100 \mu \mathrm{L}$ of this 1:500 dilution according to the manufacturer's instruction. Absorbance of the ELISA plates were measured at $405 \mathrm{~nm}$ after a $30 \mathrm{~min}$ incubation period.
The field trials were conducted in 2000 and in 2001 at the Michigan State Univ. Montcalm Research Farm in Entrican, Michigan, and the Cornell Univ. Long Island Horticultural Research and Extension Center in Riverhead, N.Y. The Michigan field location was chosen for its history of high levels of natural colorado potato beetle infestation. The colorado potato beetle population at the Montcalm Research Farm in Entrican, Mich., is known to be resistant to most insecticides, including organochlorines, organophosphates, carbamates and pyrethroids, similar to most populations present in commercial potatoes in Michigan (Bishop et al., 2001; Ioannidis et al., 1991). The experiment was replicated in Long Island, N.Y., to evaluate the performance of the host plant resistance clones against colorado potato beetle populations with high levels of resistance to most insecticides including imidacloprid (Zhao et al., 2000). The Michigan and New York research sites have been maintained and used for various colorado potato beetle field research since the 1970s and 1950s, respectively (e.g., Grafius and Blakeslee, 1978; Noling et al., 1984; Roberts et al., 1981).

Potato seed tubers were obtained from field-grown tissue culture transplants. The experimental design of the field study was a randomized complete-block design with four replications of 10 plants each. Treatment plots $(2.5 \mathrm{~m}$ long, $25 \mathrm{~cm}$ within-row spacing between plants) were planted between rows of a susceptible guard ('Snowden' in Michigan and 'Norwis' in New York) ( $86 \mathrm{~cm}$ spacing between rows) to maintain an even distribution of colorado potato beetles across field plots. Observations were recorded on a weekly basis for a visual estimation of percent defoliation by colorado potato beetles and the numbers of egg masses, larvae, and adults per plant. Data were collected until vine senescence or until defoliation levels reached $100 \%$ on the susceptible clone.

Ano-choice field cage study was conducted in 2002 at Michigan State Univ., East Lansing. Ano-choice study was important because it more closely models a commercial field situation where only one variety would likely be grown and adults would not have a choice for feeding or egg laying. For example, in our field trials, each treatment row was adjacent to a row of susceptible potatoes ('Snowden' in Michigan, 'Norwis' in New York). Females may avoid ovipositing on a less-preferred line in a varietal trial; the potato line may have few larvae and appear resistant. However, in a no-choice situation (e.g., a commercial potato field) the lesspreferred variety may be perfectly acceptable for oviposition, larval survival and development.

Plots in cages were two rows by five plants $(86 \mathrm{~cm}$ between rows, $25 \mathrm{~cm}$ between plants in a row), with three replications

Table 1. Host plant resistant potato clones (natural, engineered and combined) evaluated against colorado potato beetles (CPB) in choice field studies (Michigan and New York) and a cage no-choice field study (Michigan).

\begin{tabular}{lllll}
\hline Potato clone & Host plant resistance mechanism & Construct $^{\mathrm{z}}$ & Source $^{\mathrm{y}}$ & Parent clone $^{\text {P }}$ \\
\hline ND5873-15 & CPB-resistant $(S$. chacoense-derived $)$ & None-NT & NDSU & NA $^{\mathrm{x}}$ \\
NYL235-4 & Glandular trichomes & None-NT & Cornell & NA \\
'Norwis' & Susceptible control & None-NT & NA & NA \\
ND5c3.1 & CPB resistant $($ S. chacoense-derived $)+$ Bt-cry3A & ocs $_{3}$ mas/cry3A & MSU & ND5873-15 \\
NYLc3.3 & Glandular trichomes + Bt-cry3A & ocs $_{3}$ mas $/$ cry3A & MSU & NYL235-4 \\
NORc3.8 & Bt-cry3A & ocs $_{3}$ mas $/$ cry3A & MSU & 'Norwis' \\
\hline
\end{tabular}

${ }^{\mathrm{z}}$ Transgene construct information: ocs ${ }_{3}$ mas: trimer octopine synthase and mannopine activator and promoter; cry $3 A$ : Bt-cry $3 A$ is a coleopteran-specific insecticidal crystal; None-NT = nontransgenic potato line.

${ }^{\mathrm{y}}$ Source of plant material: NDSU = North Dakota State University, Fargo; Cornell = Cornell Univ., Ithaca, N.Y.; MSU $=$ Michigan State Univ., East Lansing.

${ }^{\mathrm{x}}$ Not applicable. 
per treatment (18 cages). Screen cages, $8 \mathrm{~m}^{3}(2 \times 2 \times 2 \mathrm{~m})$, were constructed over the field-grown plants, $7 \mathrm{~d}$ prior to adding colorado potato beetle adults to the cage. Newly emerged, first field generation adults (summer adults) were collected from the MSU Montcalm Research Farm, Entrican, Mich., and 50 adults were placed in the center of each cage on 15 July 2002. Percentage defoliation by colorado potato beetles were visually estimated and the number of egg masses, instars, and adults per plant were conducted weekly.

Percentage defoliation data were used to calculate the area under the defoliation curve (AUDC), similar to calculation of the area under the disease progress curve (Shaner and Finney, 1977). AUDC for a specific plot was divided by the maximum possible AUDC (e.g., 3300 if 100\% defoliation was present from initial observation of defoliation through $33 \mathrm{~d}$ ), converting the value to relative AUDC (RAUDC). RAUDC values provide a season-long value of defoliation over time.

All life stage data (egg masses, instars, and adults) were analyzed as the seasonal mean number of individuals per plant. Seasonal mean number of colorado potato beetles per plant was calculated by dividing the cumulative number of egg masses, instars, or adults per plant by the number of observational dates.

Data were combined across years within each field trial location following confirmation of homogeneity of variances using the $\mathrm{F}_{0}$ Max test (Kuehl, 1994). Data were analyzed as randomized complete-block designs using SAS general linear model procedure for analysis of variance (SAS, 2001). Mean comparisons were conducted using Fisher's least significant difference $(\alpha=$ $0.05)$.

\section{Results}

Bt-Cry3A CONCENTRATION In FOLIAGE. The mean Bt-cry3A concentrations for NORc3.8, NYLc3.3, and ND5c3.1 lines were $5.5 \mathrm{ng} \cdot \mathrm{mL}^{-1}, 12.1 \mathrm{ng} \cdot \mathrm{mL}^{-1}$, and $26.7 \mathrm{ng} \cdot \mathrm{mL}^{-1}$, respectively. The $B t$ concentration for ND5c3.1 was significantly higher than for NYLc3.3 and NORc3.8.

DEFOLIATION IN FIELD TRIALS. In the field trials, defoliation was greater for 'Norwis' (susceptible clone) and NYL235-4 (glandular trichome clone) in New York and Michigan than for the other clones (Fig. 1). By the end of the observational period, maximum defoliation was nearly $100 \%$ on 'Norwis' in New York in 2000 and 2001 and in Michigan in 2001; and 60\% in Michigan in 2000. Over $80 \%$ and $95 \%$ defoliation were observed on NYL235-4 in New York, and $47 \%$ and $71 \%$ in Michigan. Defoliation in field trials for all $B t$ clones was very low $($ RAUDC $<5)$. The defoliation of the combined resistance clones, ND5c3.1 and NYLc3.3, were not different from the Bt-only clone NORc3.8 and ND5873-15 at the Michigan site, but both had significantly less defoliation than ND5873-15 at the New York site. The RAUDC for the Btexpressing clone, NORc3.8, was not significantly different from the RAUDC for ND5873-15. The $S$. chacoense-derived resistance clone (ND5873-15) had significantly lower RAUDC values than NYL235-4 at both Michigan and New York sites. The greater defoliation and significant difference of the combined resistance clones may be attributed to greater colorado potato beetle pressure in New York comnpared to Michigan. This difference may also result from the genetic differences between the Michigan and New York colorado potato beetle populations, including known differences in pesticide resistance levels.

DEFOLIATION IN NO-CHOICE FIELD CAGE TRIAL. Figure 2 shows RAUDC values for the host plant resistance clones in the no-choice cage study. The defoliation pattern for the no-choice study was similar to the choice field studies, except for the consumption on the two natural host plant resistance clones NYL235-4 and ND5873-15. In the cages, 'Norwis' defoliation (RAUDC $=50$ ) was greater than NYL235-4 (RAUDC $=15)$, and the defoliation for ND5873-15 (RAUDC = 33) was intermediate between the two, but not different from either $\left(\mathrm{LSD}_{0.05}=21, P>0.001\right)$. The surprisingly high defoliation on ND5873-15 in the cages compared to the resistance observed in the field was due to extensive clipping of the petioles by the adult beetles soon after introduction to the cages. Regrowth on ND5873-15 occurred after the adults died (Fig. 5). The $B t$-lines (alone and combined) had very low RAUDC values (RAUDC range of 0.4-0.5), but values were not significantly different from the RAUDC for NYL235-4.

Colorado potato beetle life stages: Choice Field and NO-CHOICE CAGE FIELD STUDIES. In the choice field studies in New York and Michigan, the numbers of egg masses were not significantly different between the six clones (data not shown) and no patterns were observed. ND5873-15 had significantly less small larvae than 'Norwis' and NYL235-4, while the three $B t$-lines had less than ND5873-15 (data not shown). The results for the number of large larvae paralleled that of the small larvae. The cumulative number of large larvae per plant separated into two groups (Fig. 3). Higher numbers (2.4-3.0 larvae/plant) were found on 'Norwis' and NYL235-4, with lower numbers (0.0-1.2 larvae/plant) occurred on ND5873-15 and the three Bt-lines. Some of the large larvae found on the $B t$-lines likely moved from the adjacent susceptible guard rows. In comparison, in the no-choice cage study, the cumulative number of large larvae per plant was highest for 'Norwis' ( $>10$ per plant), followed by NYL235-4 (>6 per plant) and ND5873-15 (>1 per plant) (Fig. 4). No large larvae were observed on any of the three $B t$-lines.

\section{Discussion}

Colorado potato beetles have been a major defoliating pest of potato for years in the United States. Opportunities exist to incorporate host plant resistance in cultivated potato, including glandular trichomes (Tingey, 1991), leptine glycoalkaloids (Sinden et al., 1986b), uncharacterized natural resistance factors (Sikinyi et al., 1997), Bt Cry proteins (Sutton et al., 1992), vegetative insecticidal proteins (VIPs) (Estruch et al., 1996), avidin (Markwick et al., 2001), lectins (Gatehouse et al., 1993), and others. The host plant resistance mechanisms that have been incorporated in advanced cultivated potato germplasm are Bt (Perlak et al., 1993), glandular trichomes (Plaisted et al., 1992), and S. chacoense-derived resistance factors (Lorenzen et al., 2001). Incorporation of different host plant resistance mechanisms in combination will assist in deploying an integrated pest management program for colorado potato beetle in potato (Cooper et al., 2004).

Effectiveness of resistance factors in the New York trials was especially interesting because this beetle population expresses high levels of resistance to all synthetic insecticides including the newest group, the neonicotinoids (Zhao et al., 2000). At least one glycoalkaloid found in potatoes, chaconine, has been shown to act as a cholinesterase inhibitor like many insecticides (Wierenga and Hollingworth, 1993). Thus, we had hypothesized that the resistance derived from $S$. chacoense (ND5873-15) might not be effective against New York colorado potato beetles. In this case, at least, insecticide resistance does not seem to impart significant tolerance to $S$. chacoense-derived resistance. However, there is still the possibility that colorado potato beetles could rapidly adapt 


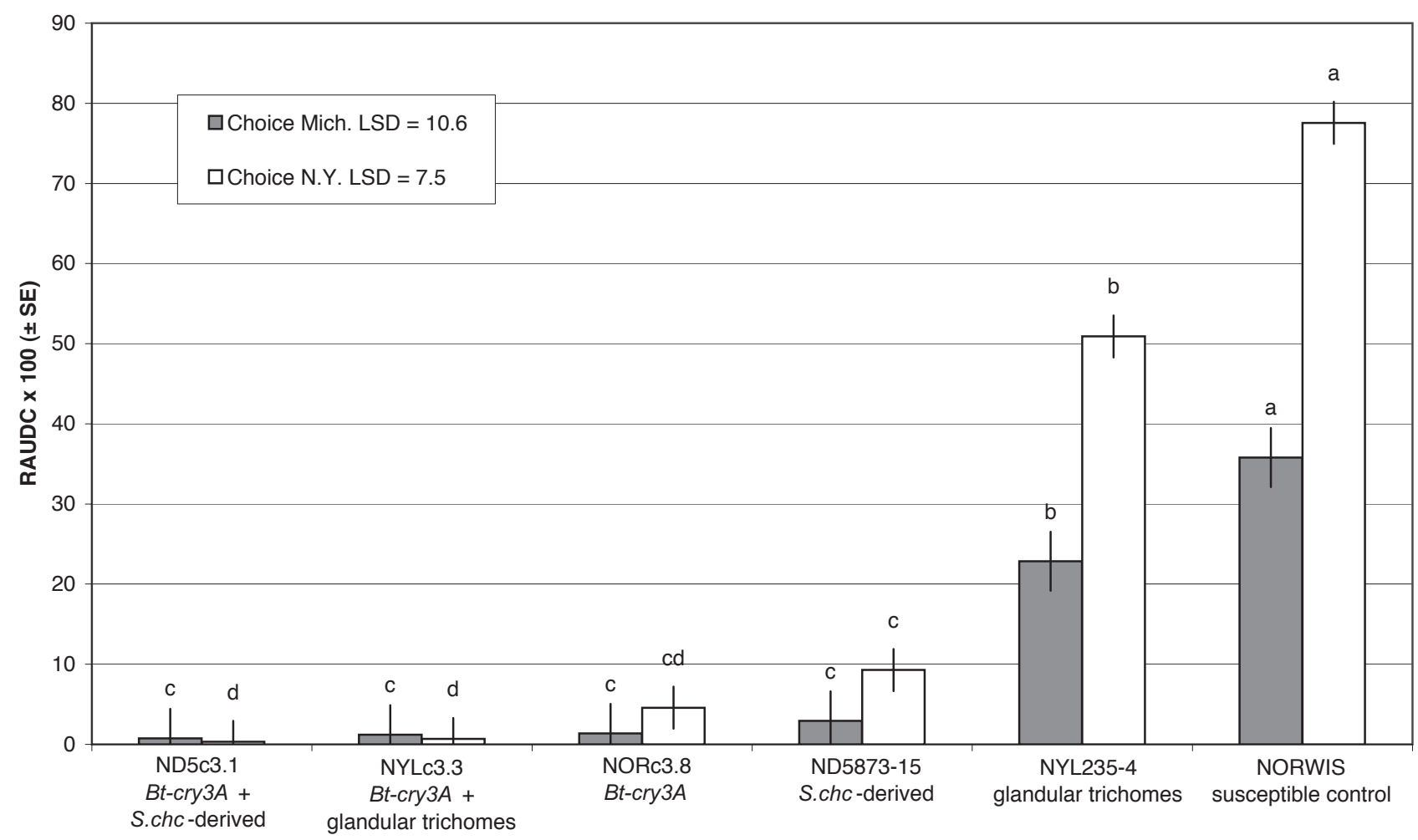

Host plant resistant potato clone

Fig. 1. Colorado potato beetle defoliation [relative area under the defoliation curve (RAUDC) values] of potato host plant resistant clones in a choice field study for Michigan (Choice Mich.) and New York (Choice N.Y.) (2000-01). Data within each location with the same letter designation are not significantly different as determined by Fisher's LSD $(\alpha=0.05)$. Error bars represent \pm SE.

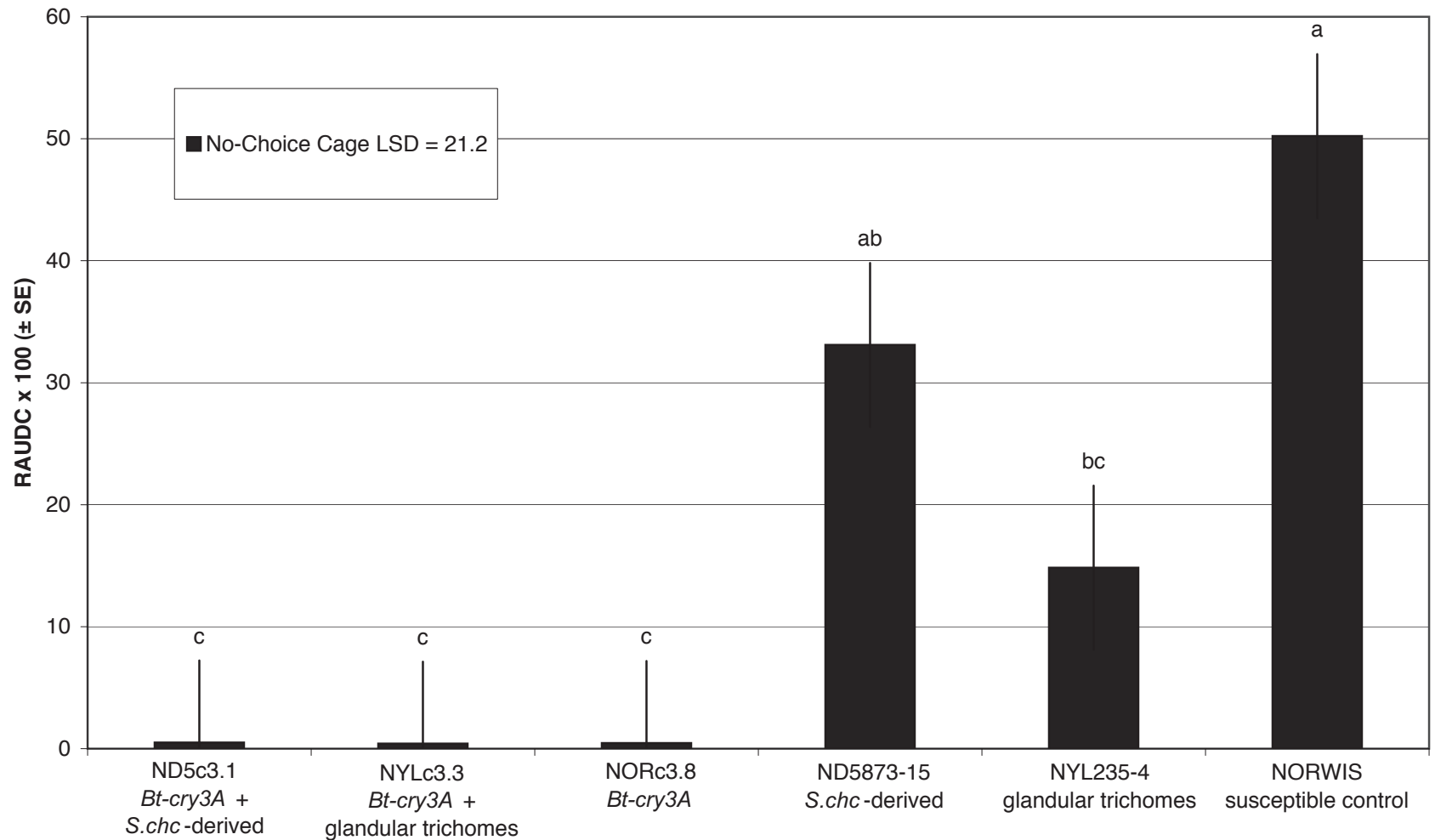

Host plant resistant potato clone

Fig. 2. Colorado potato beetle defoliation [relative area under the defoliation curve (RAUDC) values] of potato host plant resistant clones in a cage no-choice field study in Michigan (2002). Data with the same letter designation are not significantly different as determined by Fisher's LSD $(\alpha=0.05)$. Error bars represent \pm SE. 


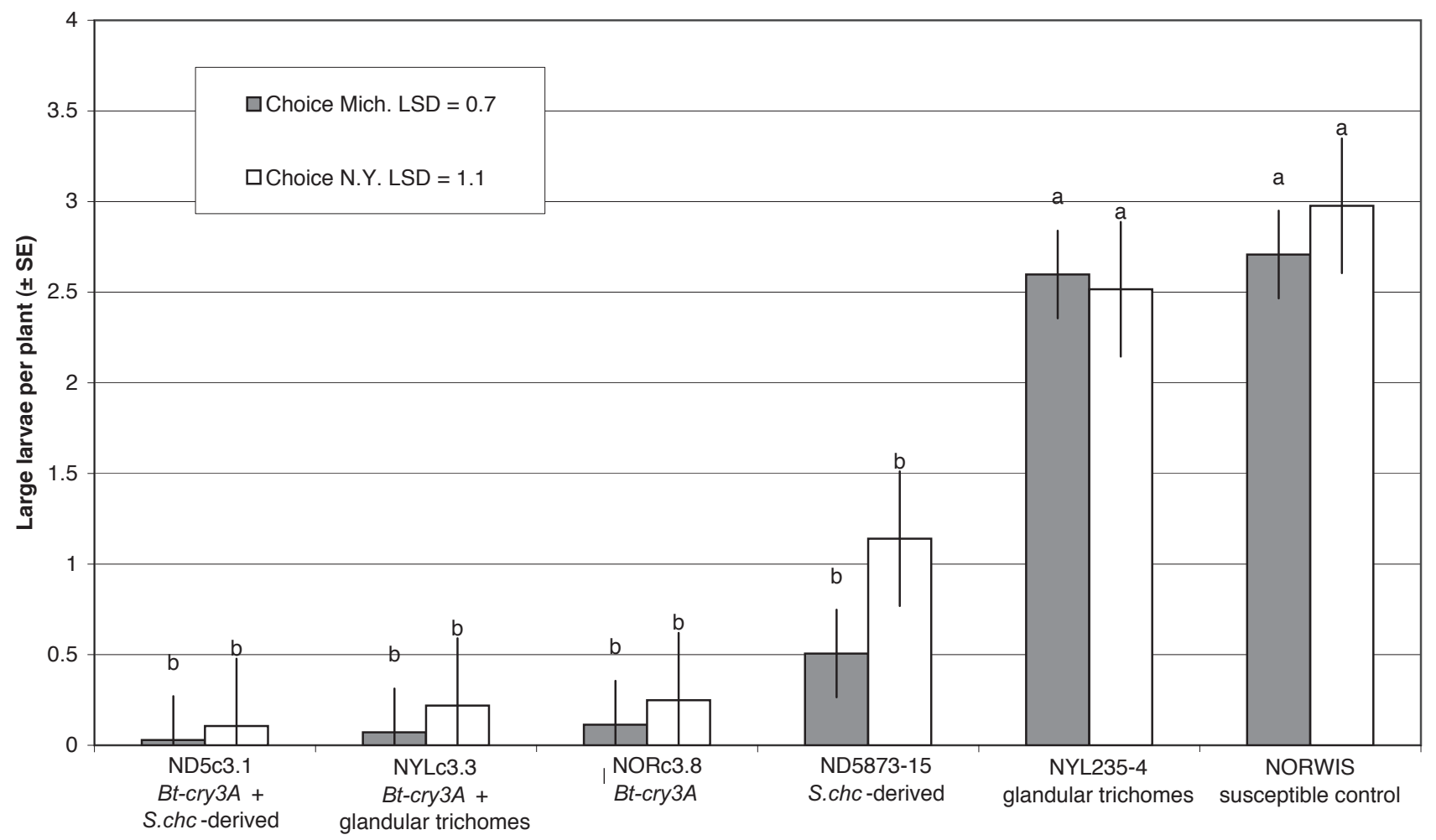

Host plant resistant potato clone

Fig. 3. Seasonal mean number of large colorado potato beetle larvae per plant on potato host plant resistant clones in a choice field study for Michigan (Choice Mich.) and New York (Choice N.Y.) (2000-01). Data within each location with the same letter designation are not significantly different as determined by Fisher's $\operatorname{LSD}(\alpha=0.05)$. Error bars represent \pm SE.

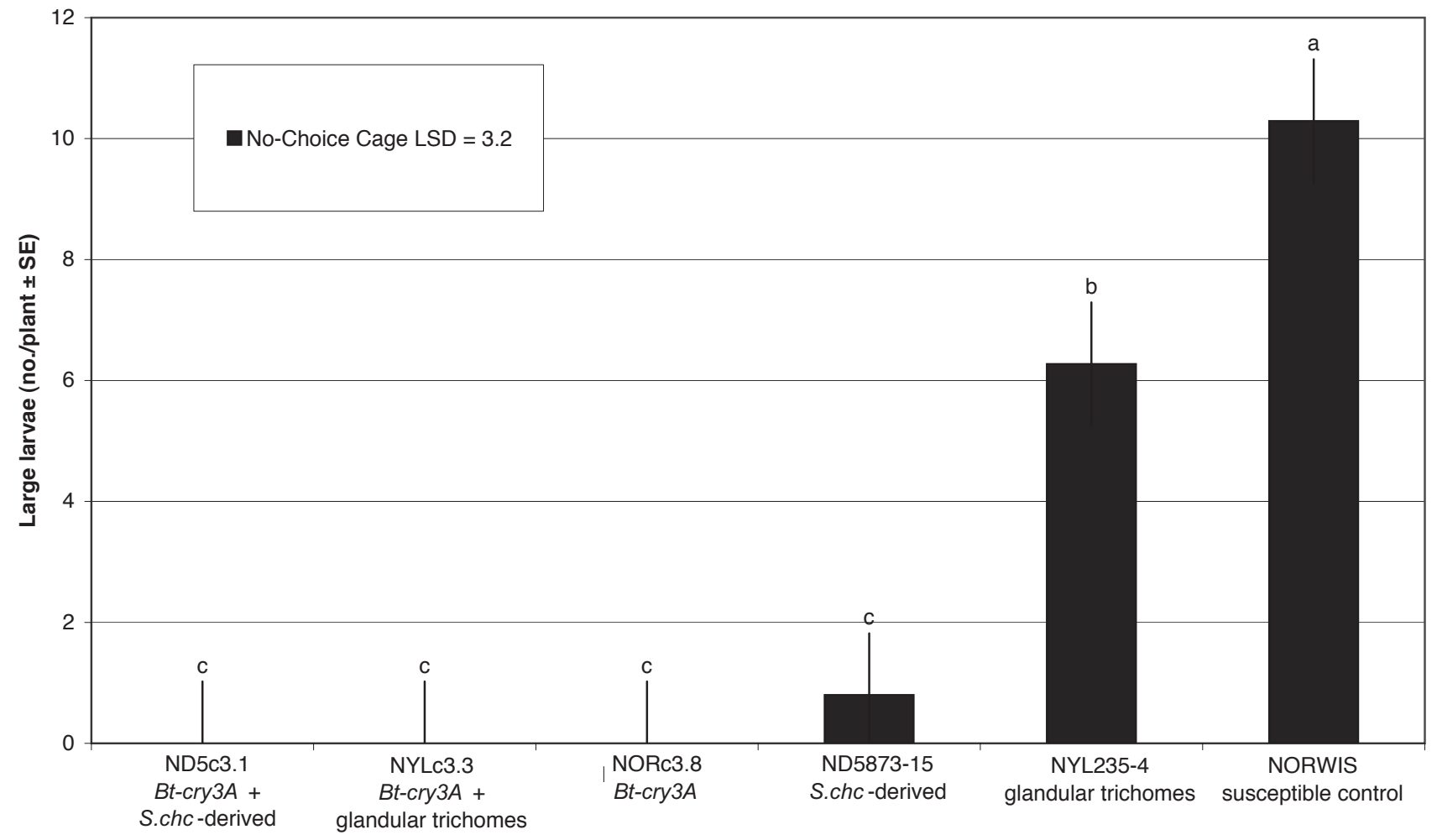

Host plant resistant potato clone

Fig. 4. Seasonal mean number of large colorado potato beetle larvae per plant on potato host plant resistant clones in a cage no-choice field study in Michigan (2002). Data with the same letter designation are not significantly different as determined by Fisher's LSD $(\alpha=0.05)$. Error bars represent \pm SE. 


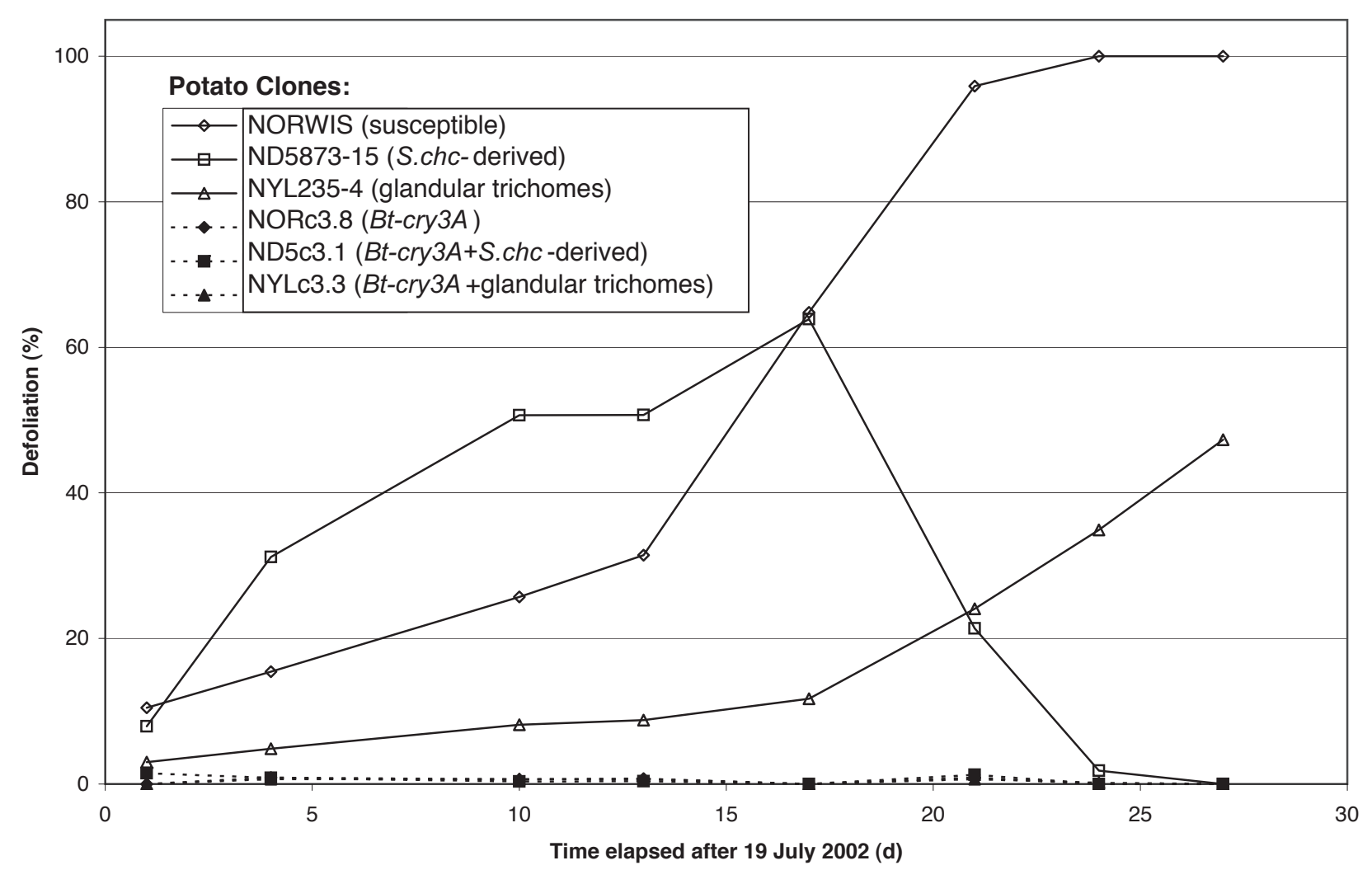

Fig. 5. Colorado potato beetle defoliation (percent per plant over time) of potato host plant resistant clones in a cage no-choice field study in Michigan (2002).

to this new source of resistance, like they have been shown to rapidly adapt to glandular trichome-based resistance (Groden and Casagrande, 1986). Combining sources of host plant resistance seems especially prudent for this highly adaptable insect.

In the New York and Michigan field tests in 2000 and 2001, colorado potato beetle adults did not demonstrate strong preference; they were found on all clones irregardless of host plant resistance mechanism (data not shown). However, although the same numbers of adults were placed on all clones in the no-choice cage trial, there were significantly fewer adults counted at later dates and delayed egg-laying on the $B t$-expressing clones. These translated to fewer larvae and subsequently less defoliation by larvae and adults. No large larvae were counted on these Btexpressing clones.

To further investigate colorado potato beetle behavior on these host plant resistance clones, adults were placed into no-choice cage trials. Based upon defoliation data, the ranking of the two natural resistance lines (NYL235-4 and ND5873-15) reversed between field and cage trials (Figs. 1 and 2). In the cage trials, relatively greater defoliation was observed on ND5873-15 than in the field trials. In detached-leaf bioassays in the laboratory, Douches et al. (2001) and Coombs et al. (2003) observed no difference in defoliation between cultivated potato varieties and NYL235-4. Collecting life stage data along with defoliation was also valuable in assessing the efficacy and comparing various host plant resistance mechanisms and colorado potato beetle behavior. This switch in ranking of the natural resistance lines between field and cage trials was not observed when seasonal mean number of large larvae per plant was measured (Figs. 3 and 4). In subsequent experiments, we have removed preference behavior of colorado potato beetle adults as a factor by placing egg masses directly onto plants in no-choice cage trials (D.S. Douches, unpublished data,).

We could not distinguish between the Bt-cry $3 A$ clone and $B t+$ natural resistance combined clones in either the choice or no-choice field trials because of the strong effect of $B t$ alone. This inability to distinguish between the lines was also found in detached-leaf bioassays (Coombs et al., 2003). However, in detached-leaf bioassays we could differentiate between $B t$ transgenic clones and $B t+$ leptines using third and fourth instars of a laboratory-selected $B t$-resistant colorado potato beetle strain (Cooper et al., 2004).

\section{Potato clones}

NORc3.8 (Bt-cry3A). The Bt-cry3A engineered resistance line was resistant to feeding at both locations. Interestingly, the foliar Bt-Cry3A level in this clone $\left(5.5 \mathrm{ng} \cdot \mathrm{mL}^{-1}\right)$ was the lowest expression level that was tested in the field. This level was 10 -fold lower than the commercially released 'Atlantic NewLeaf' (data not shown). Despite the lower $B t$ level in this clone, defoliation was significantly less than defoliation on ND5873-15 or NYL2354. Bt-cry3A alone is an effective tool in controlling feeding by colorado potato beetle; however, resistance management strategies are required for $B t$ to continue to be a viable option in the future (McGaughey and Whalon, 1992).

NYLc3.3 (GLANDULAR TRICHOMES + Bt-cry3A). In the field studies, the glandular trichome line NYL235-4 did not effectively control feeding by colorado potato beetles over the course of the season, therefore the resistance exhibited by NYLc3.3 is most likely due to $B t$-cry $3 A$. The foliar $B t$-Cry $3 A$ level is twice as high as NORc3.8 $\left(12.2 \mathrm{ng} \cdot \mathrm{mL}^{-1}\right)$. The glandular trichome $+B$ t-cry3A resistance combination may provide more broad-spectrum insect control than Bt-cry3A alone, where the Bt-cry3A confers strong 
resistance to colorado potato beetle and the glandular trichomes would be effective against other insect pests, including green peach aphid (Myzus persicae Sulzer) and potato leaf hopper (Empoasca fabae Harris) (Tingey, 1991).

ND5c3.1 (S. CHACOENSE-DERIVED RESISTANCE + Bt-cry3A). The ND5873-15 + Bt-cry3A clone ND5c3.1 was very effective in controlling feeding by colorado potato beetle in this study, although defoliation was not significantly different from defoliation of $B t$-cry3A alone (NORc3.8). In both the choice and no-choice trials, virtually no feeding was observed on ND5c3.1. This is similar to observations by Cooper et al. (2004) where little to no feeding was observed on Bt-cry $3 A+$ leptines. This combination of resistance factors should provide an effective and more durable control of colorado potato beetle than either factor alone.

'Norwis' (SUSCEPTIBLE). Colorado potato beetle pressure was greater at the New York site than at the Michigan site. This is seen with both the RAUDC values and the mean number of individuals for the susceptible control 'Norwis'. We consider the survival, development, and defoliation of colorado potato beetles on 'Norwis' in both the choice and no-choice field trials to be similar to other susceptible clones ('Russet Burbank', 'Spunta', 'Yukon Gold').

NYL235-4 (GLANDULAR TRICHOMES). The glandular trichome clone alone did have significantly less feeding than the susceptible control in all trials; however, defoliation was significantly greater than defoliation of the Bt-cry3A transgenic clones. These results do not reflect the deterrence properties of NYL235-4, which are quite strong earlier in the season when other susceptible plants are available nearby in a choice situation (data not shown). A component of NYL235-4's resistance may also be due to low levels of undefined foliar glycoalkaloids $\left(6.0 \mathrm{mg} \cdot \mathrm{g}^{-1} \mathrm{dry}\right.$ weight $)$ (D.S. Douches, unpublished data). Yencho et al. (1998) identified a quantitative trait locus (QTL) that may be contributing increased glycoalkaloid levels from the $S$. berthaultii-introgressed germplasm. The observed deterrence in NYL235-4 seems less effective later in the season when second generation adult pressure is higher and alternative susceptible plants are already defoliated. This line was also observed to resist natural potato leaf hopper infestation in our trials (unpublished data). Egg-laying and the subsequent number of larvae on this clone were significantly lower than susceptible 'Norwis' in the no-choice cage trial.

ND5873-15 (S. CHACOENSE-DERIVED RESISTANCE). The $S$. chacoense-derived resistance clone continued to demonstrate strong resistance and deterrence at both choice field locations. Resistance to defoliation in this line remained constant throughout the season. In the no-choice cage trial, defoliation ratings were initially inflated due to severe clipping of the foliage soon after introducing the adults.

We originally evaluated the North Dakota State Univ. breeding line ND5873-15 (ND4382-19 x 'Chipeta') for reported field resistance to colorado potato beetle in North Dakota trials (J.H. Lorenzen and R. Novy, personal communication). In earlier choice field trials in Michigan, ND5873-15 demonstrated strong field resistance to defoliation by colorado potato beetle (Coombs et al., 2003). Low levels of leptine (5.4 $\mathrm{mg} \cdot \mathrm{g}^{-1}$ dry weight) and higher total glycoalkaloids $\left(10.5 \mathrm{mg} \cdot \mathrm{g}^{-1} \mathrm{dry}\right.$ weight, compared to $4.0 \mathrm{mg} \cdot \mathrm{g}^{-1}$ dry weight of 'Russet Burbank') have been identified in the ND5873-15 clone (D.S. Douches, unpublished data). The resistance of this clone is most likely derived from $S$. chacoense (Lorenzen et al., 2001), although there may be other resistance factors in addition to glycoalkaloids. Sagredo et al. (2001) reported a major quantitative trait locus (QTL) different from lep- tine content that explained resistance to defoliation by colorado potato beetles; however, the main resistance factor in this clone remains uncharacterized.

Each host plant resistance mechanism evaluated in this study has its strengths and weaknesses. Combining host plant resistance mechanisms offers opportunities to construct and deploy a more durable potato variety. If the colorado potato beetle is going to be successfully controlled, an integrated approach for management is needed to incorporate durable host plant resistance, cultural practices, and chemical control. Our potato breeding philosophy and continued strategy is to combine various natural and engineered resistance sources to develop more effective and durable host plant resistance. Combining natural host plant resistance mechanisms with $B$-cry $3 A$, together with integrated management techniques, should enhance the efficacy, and more importantly, the sustainability of control of the colorado potato beetle.

\section{Literature Cited}

Bishop, B.A., A. Byrne, N. Cottrell, E. Grafius, J. Lekovish, H. Melakeberhan, M. Najera, and W. Pett. 2001. Insect management in potatoes. Michigan Potato Research Rpt. 32:106-121.

Bishop, B.A. and E. Grafius. 1996. Insecticide resistance in the colorado potato beetle, p. 355-377. In: P. Jolivet and T.H. Hsiao (eds.). Chrysomelidae biology, vol. 1. SBPAcademic Publishing, Amsterdam, The Netherlands.

Byrne, A., E. Grafius, B. Bishop, and W. Pett. 2004. Susceptibility of colorado potato beetle populations to imidacloprid and thiamethoxam. Arthropod Management Tests 29:L12.

Casagrande, R.A. 1987. The colorado potato beetle: 125 years of mismanagement. Bul. Entomol. Soc. Amer. 18:142-150.

Coombs, J.J., D.S. Douches, W. Li, E.J. Grafius, and W.L. Pett. 2003. Field evaluation of natural, engineered, and combined resistance mechanisms for control of colorado potato beetle. J. Amer. Soc. Hort. Sci. 128:219-224.

Coombs, J., D. Douches, W. Li, E. Grafius, and W. Pett. 2002. Combining engineered (Bt-cry3A) and natural resistance mechanisms in potato for control of colorado potato beetle. J. Amer. Soc. Hort. Sci. 127:62-68.

Cooper, S., D.S. Douches, and E.J. Grafius. 2004. Combining genetic engineering and traditional breeding to provide elevated resistance in potatoes to colorado potato beetle. Entomologia Experimentalis et Applicata. 112:37-46.

Douches, D.S., T.J. Kisha, J.J. Coombs, W. Li, W.L. Pett, and E.J. Grafius. 2001. Effectiveness of natural and engineered host plant resistance in potato to the colorado potato beetle. HortScience 36:967-970.

Douches, D.S., A.L. Westedt, K. Zarka, B. Schroeter, and E.J. Grafius. 1998. Potato transformation to combine natural and engineered resistance for controlling tuber moth. HortScience 33:1053-1056.

Estruch, J.J., G.W. Warren, M.A. Mullins, G.J. Nye, J.A. Craig, and M.G. Koziel. 1996. Vip3A, a novel Bacillus thuringiensis vegetative insecticidal protein with a wide spectrum of activities against lepidopteran insects. Proc. Nat. Acad. Sci. USA. 93:5389-5394.

Gatehouse, A.M.R., Y. Shi, K.S. Powell, C. Brough, V.A. Hilder, W.D.O. Hamilton, C.A. Newell, A. Merryweather, D. Boulter, and J.A. Gatehouse. 1993. Approaches to insect resistance using transgenic plants. Phil. Trans. Royal Soc. 342(1301):279-286.

Georgiou, G.P. and A. Lagunes-Tejeda. 1991. The occurrence of resistance to pesticides in arthropods. FAO, Rome.

Gould, F. 1998. Sustainability of transgenic insecticidal cultivars: Integrated pest genetics and ecology. Annu. Rev. Entomol. 43:701-726.

Grafius, E. and C.K. Blakeslee. 1978. Interactions between colorado potato beetle density, timing of defoliation and potato yield. Montcalm Expt. Sta. Res. Rpt. 10:39-43.

Groden, E. and R.A. Casagrande. 1986. Population dynamics of the colorado potato beetle, Leptinotarsa decemlineata (Coleoptera: Chrysomelidae), on Solanum berthaultii. J. Econ. Entomol. 79:91-97. 
Ioannidis, P.M., E.J. Grafius, and M.E. Whalon. 1991. Patterns of insecticide resistance to azinphosmethyl, carbofuran, and permethrin in the colorado potato beetle (Coleoptera: Chrysomelidae). J. Econ. Entomol. 84:1417-1423.

Krieg, A., A.M. Huger, G.A. Langenbruch, and W. Schnetter. 1983. Bacillus thuringiensis var. tenebrionis, a new pathotype effective against larvae of Coleoptera. Z. Angew. Entomol. 96:500-508.

Kuehl, R.O. 1994. Statistical principles of research design and analysis. Wadsworth Publishing Co., Belmont, Calif.

Lavrik, P.B., D.E. Bartnicki, J. Feldman, B.G. Hammond, P.J. Keck, S.L. Love, M.W. Naylor, G.J. Rogan, S.R. Sims, and R.L. Fuchs. 1995. Safety assessment of potatoes resistant to colorado potato beetle. Amer. Chem. Soc. Symp. Ser. 605:148-158.

Lorenzen, J.H., N.F. Balbyshev, A.M. Lafta, H. Casper, X. Tin, and B. Sagredo. 2001. Resistant potato selections contain leptine and inhibit development of the colorado potato beetle (Coleoptera: Chrysomelidae). J. Econ. Entomol. 94:1260-1267.

Markwick, N.P., J.T. Christeller, L.C. Dochterty, and C.M. Lilley. 2001. Insecticidal activity of avidin and strepavidin against four species of pest Lepidoptera. Entomologia Experimentalis et Applicata. 98:59-66.

McGaughey, W.H., F. Gould, and W. Gelenter. 1998. Bt resistance management. Nature Biotechnol. 16:144-146.

McGaughey, W.H. and M.E. Whalon. 1992. Managing insect resistance to Bacillus thuringiensis toxins. Science 285:1451-1454.

Ni, M., D. Cui, J. Einstein, S. Narasimhulu, C.E. Vergara, and S.B. Gelvin. 1995. Strength and tissue specificity of chimeric promoters derived from the octopine and mannopine synthase genes. Plant J. 7:661-676.

Noling, J.W., G.W. Bird, and E.J. Grafius. 1984. Joint influence of Pratylenchus penetrans (Nematoda) and Leptinotarsa decemlineata (Insecta) on Solanum tuberosum productivity and pest population dynamics. J. Nematol. 16:230-234.

Perlak, F.J., T.B. Stone, Y.M. Muskopf, L.J. Petersen, G.B. Parker, S.A. McPherson, J. Wyman, S. Love, G. Reed, D. Biever, and D.A. Fischhoff. 1993. Genetically improved potatoes: Protection from damage by colorado potato beetles. Plant Mol. Biol. 22:313-321.

Plaisted, R.L., W.M. Tingey, and J.C. Steffens. 1992. The germplasm release of NYL235-4, a clone with resistance to the colorado potato beetle. Amer. Potato J. 69:843-846.

Roberts, R, A. LeBrun, and M. Semel. 1981. Control of the colorado potato beetle with fungi, p. 119-137. In: J. Lashomb and R. Casagrande (eds.). Advances in potato pest management. Hutchinson Ross Publ. Co., Stroudsburg, Pa.

Sagredo, B., A. Lafta, H. Casper, and J. Lorenzen. 2001. AFLP mapping of genes controlling leptine synthesis in tetraploid potatoes. Amer. J. Potato Res. 78:479. (Abstr.)
SAS Institute. 2001. The SAS system for Windows, Release 8.2. SAS Institute, Cary, N.C.

Shaner, G. and R.E. Finney. 1977. The effect of nitrogen fertilization on the expression of slow-mildewing resistance in Knox wheat. Phytopathology 67:1051-1056.

Sikinyi, E., D.J. Hannapel, P.M. Imerman, and H.M. Stahr. 1997. Novel mechanism for resistance to colorado potato beetle in wild Solanum species. J. Econ. Entomol. 90:689-696.

Sinden, S.L., L.L. Sanford, and K.L. Deahl. 1986a. Segregation of leptine glycoalkaloids in Solanum chacoense Bitter. J. Agr. Food Chem. 34:372-377.

Sinden, S.L., L.L. Sanford, W.W. Cantelo, and K.L. Deahl. 1986b. Leptine glycoalkaloids and resistance to the colorado potato beetle (Coleoptera: Chrysomelidae) in Solanum chacoense. Environ. Entomol. 15:1057-1062.

Sutton, D.W., P.K. Havstad, and J.D. Kemp. 1992. Synthetic cry3A gene from Bacillus thuringiensis improved for high expression in plants. Transgenic Res. 1:228-236.

Tabashnik, B.E. 1994. Evolution of resistance to Bacillus thuringiensis. Annu. Rev. Entomol. 39:47-79.

Tingey, W.M. 1991. Potato glandular trichomes: Defense activity against insect attack, p. 126-135. In: P.A. Hedin (ed.). Naturally occurring pest bioregulators. Amer. Chem. Soc. Symp. Ser. 449. ACS Books, Washington, D.C.

Wierenga, J.M. and R.M. Hollingworth. 1993. Inhibition of altered acetylcholinesterases from insecticide-resistant colorado potato beetles (Coleoptera, Chrysomelidae). J. Econ. Entomol. 86:673-679.

Whalon, M.E., D. Mota-Sanchez, and L. Duynslager. 2004. The database of arthropods resistant to pesticides. $12 \mathrm{Apr}$. 2005. <http://www.pesticideresistance.org/DB/species_profile.php? arthropodid=34>.

Whalon, M.E., D.L. Miller, R.M. Hollingworth, E.J. Grafius, and J.R. Miller. 1993. Selection of a colorado potato beetle (Coleoptera: Chrysomelidae) strain resistant to Bacillus thuringiensis. J. Econ. Entomol. 86:226-233.

Yencho, G.C., S.P. Kowalski, R.S. Kobayashi, S.L. Sinden, M.W. Bonierbale, and K.L. Deahl. 1998. QTL mapping of foliar glycoalkaloid aglycones in Solanum tuberosum x S. berthaultii potato progenies: Quantitative variation and plant secondary metabolism. Theor. Appl. Genet. 97:563-574.

Yencho, G.C. and W.M. Tingey. 1994. Glandular trichomes of Solanum berthaultii alter host preference of the colorado potato beetle, Leptinotarsa decemlineata. Entomol. Expt. Appl. 70:217-225.

Zhao, J., E. Grafius, and B. Bishop. 2000. Inheritance and synergism of resistance to imidacloprid in the colorado potato beetle (Coleoptera: Chrysomelidae). J. Econ. Entomol. 93:1508-1514. 